\title{
Disintegration of the Self-Structure Caused by Severe Trauma
}

\author{
Vito Zepinic \\ Psychclinic P/L, London, United Kingdom
}

Email address:

vito@psychclinic.net

\section{To cite this article:}

Vito Zepinic. Disintegration of the Self-Structure Caused by Severe Trauma. Psychology and Behavioral Sciences. Vol. 5, No. 4, 2016, pp. 83-92. doi: 10.11648/j.pbs.20160504.12

Received: April 21, 2016; Accepted: June 18, 2016; Published: June 21, 2016

\begin{abstract}
Severe trauma affects all structures of the self - one's image of the body; the internalized images of the others; and one's values and ideals - and leads to a sense that the self-coherence and self-continuity are invaded, assaulted, and systematically broken down. The traumatic events overwhelm the ordinary human adaptations to life and generally involve threats to life or bodily integrity, confront human beings with the extremities of helplessness and terror, and evoke the response of catastrophe. The vulnerable self-structure of traumatized individuals is evident in the following ways: (a) difficulties in selfregulation (self-esteem maintenance, lower tolerance levels, and the sense of self-discontinuity and personal agency), (b) appearance of the clinical symptomatology (frequent upsurges of anxiety/fear, depression, and specific fears or phobias regarding the external world or one's own bodily integrity), and (c) reliance on primitive or less-developed forms of the selfobject relatedness. Severe trauma may lead to de-centering of the self (self-at-worst), loss of groundlessness and a sense of sameness, self-discontinuity and ego-fragility, leaving scars on the one's 'inner agency' of the psyche, fragmentation of the egoidentity resulting in proneness to dissociation.
\end{abstract}

Keywords: Trauma, Self-Structure, Self-(dis)Continuity, Disintegration of the Self, Inner Conflicts, Dissociation

\section{Introduction}

The main aim of this article is to give a contribution to the wide and complex issues that appeared as outcomes of the severe traumatic experience: the impact upon the self and abyss experience of the human suffering. The ways of one's response following traumatic exposure are evaluated in theory and clinical practice based on multiple factors: the circumstances of the trauma, reactivation of a latent trauma from the traumatic past, the phases of the development at which trauma occurs, and the social/personal context during and after the trauma [1]. Natural disasters such as cyclone or tsunami and manmade-disasters such as war, terrorist attacks, killing, robbing, sexual and physical abuse, and plane crashes show how vulnerable we are [2].

The psychological sequelae following traumatic experience are usually domino-like progression of the stressresponse reactions. In case of severe trauma, it could permanently alter the self-cohesion and self-continuity of the trauma victim. This process of disintegration of the self may occur in two ways: (1) consciously expressed concerns related to weak, vulnerable, and defective sense of self, and (2) out of the person's conscious awareness, disintegrated self is seen as a danger to the traumatized person and to the others. As consequences of the self-discontinuity, the trauma victim is flooded with intrusive memories of the trauma, as well as thoughts, images and dreams (nightmares) with compounded levels of hyperarousal or flashbacks $[3,4,5,6]$.

When clinical symptoms such as flashbacks, nightmares or other sleep problems, difficulty concentrating, and emotional liability are mild and have been present for more than four weeks after traumatic event, the early psychological intervention in form of debriefing has no effect in preventing post-traumatic stress disorder, in addition debriefing might be even harmful [7]. The standard practice of debriefing after either natural or man-made disasters and catastrophes, severe fears or phobias after terrorist attack, could strike further development of severe stress-related condition because of re-traumatisation of fresh traumatic experience. The risk of developing posttraumatic stress disorder after trauma is $8-13 \%$ for men and 
$20-30 \%$ for women, with a 12 -month prevalence of 1.3 to

3.9 , creating a huge burden on the victim $[8,10]$.

Post-traumatic stress disorder is primarily a deregulation of the fear system as the fear is a necessary emotion at times of danger, and is followed by a stress response - fighting, freezing, or fleeing. The survival system depends on appraisal threats in order to activate initial survival skills [9]. Once the threat or trauma is over, the fear system in posttraumatic stress disorder fails to reset to normal condition keeping the sufferer hyper-alert, scanning for dangerous cues as if the event will happen again. The spectrum of one's personality pathology caused by trauma has a significant implication on the empirical and theoretical sentiments but more importantly on the demands in treating the tormented self [1]. An empirically sound diagnostic system should facilitate reliable findings on how much trauma changed or destroyed one's personality - the sense of self - its cohesion and continuity.

Trauma is an unpredictable experience that could change all structures of the normally desired personality wholeness and functioning. In theory and clinical practice, the real understanding and description of the trauma impact on one's personality is an open-ended task. For those who have experienced trauma of different co-morbidity and malignancy, life is almost simply not worth living. Their lives are usually affected in all areas of functioning: daily living, relationship to their own self, relationship with others, including intra-psychic conflicts and coping mechanisms. Trauma survivor's suffering and pain are related to the horrible traumatic memories which overwhelm one's capacities to cope and to be a 'person'. The horrible traumatic memories are like a volcano which can erupt at any time causing the unpredictable consequences and damages on the trauma victim's personality. The traumatized personality is an iceberg for the clinicians - the iceberg which cannot be seen in whole [11].

The complex trauma is analogue to a high-velocity bullet piercing through the body, tearing apart internal organs which are critical for survival [12]. Like the brain and the heart are the critical organs for the body's existence, the self-cohesion and self-continuity are the core psychic elements for a psychological equilibrium. As the brain and the heart are essential structures with interrelated functions, the selfcohesion and continuity are dynamically interrelated in psychological growth of a human being. Without meaningful way to understand the traumatic damages to the self, it would be like trying to understand degenerative neurological disorders without understanding how the brain functions.

Traumatized individuals usually experience a 'black hole' of their inner world - its structure is shattered, torn apart into pieces causing depleted sense of the self and its continuity. It makes the trauma victim often malignant in self-loathing, very suspicious and mistrustful towards others, even to the own self. Trauma experience may leave psychological wounds so disabling that the entire person feels incompetent, devastated, hopeless, and remorseful. The concept of a spectrum or complex suffering has been suggested by many clinicians (Kardiner, Myers, Briere, Courtois, Foa, Herman, Horowitz, van der Hurt, Keane, van der Kolk, Yehuda, among others) who are united in opinion that a prolonged or repeated trauma (chronic trauma) causes long-term effects which do not fit or can be diagnosed as a single disorder neither under DSM or ICD classification. Chronic traumatization causes more complex and severe symptoms than described in the diagnostic criteria for PTSD as a single disorder - the clinical trials have emphasized the severity of syndromal concept of the personality changes: (1) alterations of ability to modulate emotions, (2) alterations of identity and sense of self, (3) alterations of ongoing consciousness and memory, (4) alterations in perception of the perpetrator, (5) alterations in relations with others and intimacy, (6) alterations in physical and medical status, and (7) alterations in systems of meaning [1].

\section{Complex Trauma Syndrome Pattern}

Any definition of the complex trauma, at very last, addresses the findings of its specific and complex nature, comorbidity, and symptomatology. There is a united agreement among the clinicians that those who were exposed to severe, repetitive, or prolonged stressors should be seen as they are under the risk of suffering complex trauma syndrome. To explain trauma symptoms, it is important to consider how much exposure to a life-threatening situation became conditioned to a wide variety of stimuli during the traumatic experience.

In case of prolonged or repeated trauma, the victim is totally powerless and the victim's entire personality functioning is shaped by the perpetrator's or torturer's demands. In complex trauma cases, clinical experience usually revealed a history of demands to blindly follow violent behaviour with the perpetrator's intention to control every aspect of the victim's life. The ultimate demands are to create a willing victim compliant to the perpetrator's relentless demands, gratitude, or even love. On the other hand, the trauma victim is losing the own identity and the self with gradual functions deterioration of the self [12]. As trauma inflicts a terror and fear which are increased by the inconsistent and unpredictable outbursts of enforcement against the victim's self, the trauma inevitable leads to the losses of one's autonomy and all aspects of independent functioning, and even basic desire to survive [9].

The trauma paradigm of a complex trauma differs from the thesis of the diagnostic features of PTSD, which is larger and more complex. To understand the theory of complex trauma, it is necessary to clarify the traumatic event as an external event, causing severe psychological and/or physical upheaval with lasting and crushing consequences on the inner state of the self and its fragmentation. The sense of self and self-object losses are seen as the key to the physiology of traumatization, and the stressor event and the self-system as ancillary to such losses $[1,13,14]$. Those who are victimized are, usually, unable to understand, accept, or comprehend the trauma experience: they rather would disappear, if possible, 
from the real world which to them seems unsupportive, hopeless, and dangerous place for leaving.

The diagnostic conceptualization of the complex trauma is characterized by three major domains [12]:

- The repeated reliving of traumatic memories which involves intense sensory and visual memories of the traumatic event accompanied by an extreme physiological and psychological distress and feelings of emotional numbing. The intrusive memories can occur spontaneously or can be triggered by a range of real or symbolic stimuli.

- Avoidance of reminders of the trauma-numbing, detachment, and emotional blunting which coexist with an intrusive recollection of the event. Intrusions are associated with an inability to react and experience a joy and pleasure, commonly followed by total withdrawal from any engagement in life.

- Increased arousal with the hyper-vigilance, irritability, memory and concentration dysfunctions, sleep disturbances, and an exaggerated startle response. Traumatized people are easily distressed and distracted by an unexpected stimulus. Their perceptions are excessively focused on the search in finding the similarities between the present and the traumatic past, usually reinterpreting neutral experience associated with the traumatic event.

The complex trauma paradigm is unique and differs from the thesis of single stress disorder diagnostic features $[3,15$, $16,17,18,19,20,21]$. Complex trauma involves stressors that (1) are repetitive and prolonged, (2) involve direct harm and/or direct threat to trauma victim, (3) occur at a vulnerable time in the victim's life, and (4) have severe impact on the victim's entire life and personality [22].

Research and clinical experience of complex PTSD are centered on the hypothesis that complex traumatic experience (complex trauma) lead to a post-traumatic syndrome rather than a single disorder [62]. The terms complex trauma and complex PTSD are often used interchangeably, a practice which can lead to confusion. It is proposed [16] distinction between these two phenomena referring the complex trauma as a complex traumatic experience (prolonged or/and repeated trauma), and the complex PTSD as a complex of post-traumatic symptoms (trauma syndrome). However, in most evaluated severe symptomatology of PTSD (in particular before DSM-5 and ICD-11), the clinicians rather use term complex trauma than complex PTSD. The clinicians are united that a longer course of treatment might be necessary for the effective treatment of complex PTSD which is defined by the presence of a stable negative (disintegrated) self-concept (integrity and coherence) and avoidance of relationships [17, 23, 24, 60].

The experience of war, either as a combat or war imprisonment, is the most devastating traumatic experience (complex trauma) and more complicated traumatic event than delineated traumatic events, such as robbery, natural disaster, or traffic accident. In general, traumatic events done by the human beings, such as rape [25], and torture [12, 17, 20, 26], are more impacting on the victim's personality than the natural disasters. The traumatic experience caused by man-made disasters strengthens the development of negative emotional and cognitive schemes about the self and the others.

In order to understand the complexity and severity of complex trauma, evaluation should clarify the nature of traumatic event that caused a severe psychological upheaval with lasting and crushing consequences on the inner state of the self and its fragmentation [1, 27, 28, 29]. The negative emotional and cognitive schemes caused by complex traumatic experience can persist permanently and, as a result, the traumatized individuals are more vulnerable to develop and/or maintain other disorders (psychosis, depression, personality disorders). Even during therapy, trauma victims show avoidance of thinking or recalling about distressing thoughts or memories of trauma. Subsequently, over the course of years, this habitual coping style fulfilled with negativism and distortions may translate into the avoidance of negative memories in general and may even apply to memories that are unrelated to traumatic event(s).

As outcomes of the severe trauma, the traumatized individuals have been characterized by avoiding coping style in which emotional inhibition such as thought suppression are utilized in order to avoid experiencing distressing thoughts or memories in general [30, 54, 55, 56]. Any attempt to suppress certain traumatic memories may lead the traumatized individual to preoccupation and an increase in the occurrence of these memories or thoughts which can evoke at any time when the individual no longer is trying to suppress traumatic memories or thoughts.

\section{Traumatic Memories of Complex Trauma}

The evaluation of traumatic memories is a 'traumatic puzzle' for the clinicians and the patients. We assume that traumatic memories should be seen as a construct of trauma survivor's life, which is only partly assessable and it is also partly accessible to consciousness at a given time. The victim's traumatic memory system (emotions, cognition and tendencies to respond) is fulfilled with stored unconscious and triggered traumatic material. Consequently, many of the essential elements of therapy of complex trauma - transference, working through and restructuring - involve working with traumatic memories $[6,15,16,21,32,33]$. There is an understanding regarding distinction between the implicit and explicit memory suggesting that traumatic experience is recorded and then recalled and expressed by different meaning (conscious $v$ unconscious, narrative $v$ behavioral) varies. In case of complex trauma victim, the traumatic memories are personal memories of the traumatic experience (event) and not the memories that could be a part of any time expected event [57]. It is also common that in severe trauma experience the victim's memory system coded partial sequences and such remembering is presumably resulted from a narrowing range of the perceptual field, enhancing the memory for the limited 
information stored at the expense of information outside the focused object. This phenomenon is an altered state of consciousness resulted in the exclusion of the experience or perceptual data that normally should be present in conscious awareness [12, 34, 58].

Partial sequences of the traumatic experience are in particular important in case of the court proceedings for a crime committed against person, such as serious violence or rape. For example, in case Prosecutor v A. Furungija [1998] ICTY in The Hague (Netherlands), the prosecutor tried aiding and abetting the brutal and repeated rape by drunken paramilitary. The defendant's lawyers suggested that the woman's memory was inaccurate, because it had been adversely affected by her traumatic experience, and that the defendant she identified in fact was not present at the time when she was raped. The prosecutor disagreed and with expert's opinion it was submitted that traumatic memories of traumatic experience are outside the range of usual human experience.

In essence, traumatic memories are an imprint in which the settings and measures are out of the individual's ability to control [56, 59, 61]. Traumatic event(s) causes disruptive effect on the encoding and integration of the event(s) in memory through mechanism called peritraumatic dissociation. In clinical practice it is common that patients have difficulties in intentionally retrieving a complete memory or particulars of the traumatic event(s). The trauma victim's intentional recall is often fragmented and poorly organized, relevant details may be missing and there may be difficulties recalling the exact temporal order of the event(s) [35].

The concept of traumatic memory being incomplete, fragmented, or incoherent is fairly clear [36]. The traumatic memories can be so overwhelming that they cannot be integrated into the ordinary, existing, normal mental processing; consequently, they are encoded differently. In clinical practice we are mostly focused on explicit memory (conscious voluntary and involuntary recall) as these memories of traumatic event play a central role in understanding trauma. On the other hand, implicit memory mostly represented by flashbacks, occurs as unconscious representation of the inner conflicts and significantly contributes to the understanding of post-traumatic stress disorder. Traumatic memory applies strongly to remembering the subjective states, such as emotions, as well as not to remembering the objectively observable information [37].

Traumatic memories represent the intrusive return of an unassimilated material in a fragmented, sensory, affective, and motoric form. As traumatic event(s) causes that trauma is encoded, the effect on the victim's self-structure is proportionate to the trauma continuation and its complexity. When trauma is prolonged over days or even weeks, the affect upon the self-structure may cause severe dissociation as an adaptive defense. Thus, the dissociation allows the trauma victim to survive; however, when the trauma is over, the victim will often dissociate many affects out of awareness.

Because the traumatic experience of being automatically assimilated without conscious awareness, the severely traumatized individuals usually cannot recall details about the particulars of the event. The traumatic schemata could be remembered with specific vividness of the central traumatic code but not the entire event which was not integrated (memorized) as a whole. Under the extreme distress of complex traumatic experience, the existing schemas are unable to accommodate frightening experiences, which causes the memory particulars of these experiences to be stored differently. Those exposed to severe trauma, experience a speechless terror [20], where organisation of the traumatic experience is without semantic representation.

Based on clinical experiences of the severe trauma victim's coding and partially re-calling traumatic experience, the clinicians [3, 20, 38, 39] introduce four features that distinguish the traumatic (intrusive) memories from the normal narrative memories:

- Traumatic memories are composed of images, sensations, affective and behavioural states, whereas narrative memory is semantic and symbolic and may not be conveyed verbally.

- Traumatic memories are inflexible and invariant over time, whereas narrative memories serve social and adaptive functions.

- Traumatic memories cannot be evoked by will but are automatically elicited under specific circumstances reminiscent of the original event; once an element of the memory is stimulated, the retrieval floodgate open, and the other elements are recalled (re-experienced). In contrast, narrative memories are generally accessible without triggers and they do not bring with them an irrepressible constellation of associated affective, somatic, and motoric experiences.

- Traumatic memories, which effectively reconstitute some or all of the trauma through behavioural reenactment or intra-psychic replay, take time to remember, whereas narrative memories are verbal distillations that may be condensed or expanded on social demands.

The vivid and disturbing experience of a flashback, or reliving the traumatic event in one's most profoundly disturbing intrusion are the most severe symptoms in the post-traumatic reaction. The flashback episodes can last from a few seconds to several hours, when the traumatic event is not only remembered but also re-experienced with all its horrible effects on trauma victim's personality. Flashback reflects a state of absorption into content or fragment of a memory or a belief and its attendant affect is so profound that the current environment is largely ignored and the individual is temporarily unable to distinguish traumatic memory from the present experience. Such flashbacks or reliving of the event may be triggered by environmental stimuli reminiscent of the trauma and may occur even decades after the original trauma event $[11,49]$.

The clinicians are united in opinion that the traumatic memories are unique and show that they are: (1) primarily imprinted in sensory and emotional system, (2) remain stable over time and unaltered by here-and-now circumstances, (3) 
may return at any time triggered by a remainder with a vividness as if trauma occurs again, and (4) imprinted deeply in mental state making trauma victim unable to articulate what they think and feel [1]. Being triggered by the reminder, the memories of the traumatic past can be relieved with sensory and emotional intensity that makes victims feel as if the events were occurring all over again [29]. Traumatised person seems to remain embedded in trauma as a contemporary experience and often becomes fixated on the trauma. As traumatic memories are so fragmented and disconnected it is reasonable to postulate that extreme emotional arousal leads to a trauma victim's failure to synthesise and integrate sensations related to the trauma into an integrated whole [1].

\section{Domains of the Traumatised Self}

The domains of the self are constituted of the actual self, which is one's representation what he believes he has; the ideal self that represents one's desired image of what he would like to possess; and ought self which is one's representation of the attributes that others believe he should possess. Human beings are born with an innate psychological system that motivates them to seek proximity and affection to significant others. The self-concept guides interactions with the attachment figures in order to bid for proximity and support, promote a stable relatedness and connectedness, security and the self-promotion, and to build positive representations of self and others.

The discrepancies between the self-concept and personal self-guide, that may occur due to the trauma, have specific impact upon the self-coherence and emotions. Traumatised individual fails in seeking proximity and affection, making trauma victim unable to relieve distress, feels that his security is undermined, forms negative models of self and others, and likely his emotional problems and maladjustment increases. Such phenomena occur due to a violation of personality and shame upon the self by trauma. Clinical experiences $[1,15$, $16,17,20,21,26,50,51]$ indicate that attachment of the traumatised individual can be measured in terms of two dimensions: attachment-related anxiety (fear) and avoidance.

Trauma victim's position on the anxiety (fear) dimensions indicates the degree to which he worries for the own self and loved ones. The avoidance dimension indicates the extent to which trauma victim distrusts own and others good will and strives to maintain self-reliance and emotional distance. The trauma victims see own self as the self-at-worst and a failure to defend its cohesion and continuity from the existence of continue fears or feelings of threat. Fears represent anticipating effect from the traumatic experience which the self has not been able to manage. The more one will suffer fears or feelings of threat, the more the self-structure discrepancy will occur $[1,52,53,58,61]$.

The trauma victim's avoidance tends to rely on deactivating traumatic strategies - trying not to seek proximity, denying attachment needs, and avoiding closeness and interdependence in relationships with others [40]. These avoidance strategies not only impact trauma victim's relatedness but his view of the world as a dangerous place. In order to disapprove any closeness and expressions of need or vulnerability is a trauma victim's persistence of the proximity-avoiding strategy. Any attachment or relationship is seen as meaningless and unreliable. Such strategy interferes the development of security, stable mental foundation; it reduces resilience to traumatic experience and predisposes a person to break down psychologically.

Attachment insecurity can be seen as a general vulnerability with particular symptomatology of the traumarelated disorders [41]. Such attachment dysregulation as a component of traumatised personality, includes identity confusion, emotional liability, cognitive distortions, submissiveness, oppositionality, self-harm, suspiciousness, desperation, incompetence, and uncertainty. Because of the traumatic experience, the trauma victim is afflicted, he/she does not know where the danger is going or coming from, his/her consistency is constantly under threat by the perceived need to worry even when there is no apparent reason. Constant tension produces severe stress resulting in symptoms such as nervousness and timidness, nausea, anger, chest pressure, cardiac palpitations, shortness of breath, loss of weight or obesity, muscle spasm/ pain, persistent headaches, stomach pains, weakness, problems with intimacy, restrictive expression of emotions, and so on. It is also common that conversion reactions develop into various physiological symptoms such as pain, muscular spasm, paralysis, mutism, and loss of hearing, or psychological blindness [12].

Understanding trauma impact upon the self-structure is a quite complex matter and, in spite of long history of theoretical and clinical explanation of the connectedness between the trauma and the self, this problem is still present with many uncertainties. [42] stated that understanding traumatic impact to the self and the spirit, is like understanding a gigantic steroid's impact on the planet. This figurative and comparative explanation is reasonable as the assessment of trauma impact on the victim is an iceberg in the clinical practice [28]. In complex trauma cases there is the internalised fear for repetition of trauma and, as the self is seen as powerless or failure, the person is disconnected from the own self. Overwhelmed by the trauma, the self-structure suffers an inversion of its cohesion and continuity with the reversal of normal, consensual reality and functioning. Inversion experience is associated with altered states of awareness, perception, cognition, and motivation in which the understanding of reality inverts its order, function, and structural integrity [42]. This state of inversion is recognized in many trauma victims who dissociate as their reactions are response to the feeling of continue threat, fear, and anxiety. The damaged or inverted self-structure is not able to bring trauma victim to an ordinary (at the trauma level) adaptive capacity, autonomy, energy, and vitality. The individual's understanding of the reality (here-and-now circumstances) is succumbed and altered, with only the existing survival skills used during the trauma experience. This co-morbid state of the 
self-structure overwhelms the capacity for processing a new the traumatic past (as in Table 1). materials or experiences in any way other than connected to

Table 1. Some aspects of self-disorganisation caused by trauma.

\begin{tabular}{ll}
\hline Domains & Disturbance types \\
\hline Sensations/perceptions & bad sensation, disturbed perception (e.g. pain in different anatomical parts, coldness, hot flashes) \\
Capabilities of the self & incapable of doing or adapting, or doing worse and worse, loss of competence and power \\
Interest in others & losing relationships (e.g. being ignored, rejected, unliked, unloved, worthless, useless, insecure), no attention \\
Integration of the self & sense of fragmentation, conflict, discontinuation, disharmony, doubt, disintegration \\
Beyond the self & chaotic and confusing sense of loss, fear of trauma experience again, loss of self-structure boundaries, disunion of the self \\
\hline
\end{tabular}

Severely traumatized self has very low capacity to regulate and modulate fluctuation in the self-values (devalued representation of the self), as self-structure is highly impaired and incapacitated. The major features of traumatized self are its ongoing disintegration of cohesiveness and wholeness, and doubted sense of the reality. Traumatized self is often seen as the as if construct - nothing is clear and real $[5,52,53]$.

\section{Traumatised Self-Structure}

Because of trauma the self becomes dysfunctional and tormented and denote most, if not all, of its concepts into negative forms. The self not anymore represents a united person-body construct, mental contents, attributes, and the like $[5,14,43,45]$. Because of the traumatic experience, the self-representation or self-schema is defensively transformed into counterparts of its pre-trauma self-structure. Traumatised self is characterised by lack of self-cohesion, doubts about one's internal coherence and continuity, unstable self-esteem, and over-dependency on other people's approval with feeling of hopelessness and worthlessness. For the severely traumatized individuals, the self-structure is tied by the life experiencing in post-trauma time and, in some trauma survivors, it is tendency to define their life as a victimized person with limited expectations that someone can experience or achieve in life [1].

With the most trauma victims there is an evidence of struggling to make sense of life with hopes that somehow the self-structure will be improved when the trauma is over. However, due to rigid ways of interpersonal relatedness, any attempt to restore damaged self-structure is associated with many failures, making one's intention of a continuous sense of self as a whole and cohesive unachievable. Positive thoughts, roles, and related constructs are desirable, but the traumatised individuals are unable to process any challenges outside trauma construed schemata. Since the clinicians are agreed that the self is an integral, organizing structural part of personality and establishes bases of self-worth and uniqueness to individual identity, any impact on its cohesion and continuity impacts the entire personality and functioning. In essence, the self is a central processing unit of personality which establishes and organizes the energy and values, connections, relations, and components of identity formation - organizes experience and adaptation of personality.

In the case of the traumatized individual, the self remains torn apart and incomplete within lost unity and its wholeness - the self-structure is no longer stuck together as a whole. Overwhelmed by trauma, the self loses its fundamental interrelatedness, wholeness, and reality, and exists out of its structural components. In normal and undisturbed self, the conscious and unconscious parts fluctuate within the united self-harmony, interconnected into self-structure as a whole $[5,13,18]$. In normal circumstance, the self is always active - it involves changes, variety, refurbishment, elevation, power, and freedom in action. It is a continuing process, not static, of progressing and sequencing in its upgrading. It is composed of a common sense of the natural growth of the self-cohesion and self-continuity, and not its fragmentation, discontinuation, or disturbances.

Traumatized personality is characterized by disturbances of the self-structure or self-concept in three related categories: (a) material (body, family, material possession), (b) social (recognition from others and the acknowledgment of others), and (c) spiritual (inner experience, values, and ideals). These inevitable causes disordered awareness of the trauma impact affecting trauma victim's social experience (relatedness, attachment) which largely leads to pathological relationships with others, even with the own self [46]. The self as an integral, organizing and structural part of one's individual personality which contains the basis of the selfworth, a sense of well-being, and uniqueness of the individual identity and social belongings. The self is a significant and essential part of the one's relations, connections, and value in the others. This also helps others to recognize and value individuality, and the importance of an individual within a group or the society. The self plays a vital role in processing the personality that organizes an experience and adaptation.

In a trauma victim there is a disintegrated self as a whole and its cohesion and continuity usually involve failures in emotional attunement of the self-object (particular individual or entire external world). Normal cohesive self represents a primary motivational property guiding one's behaviour, affect, and relationships, however, the disintegrated (traumatised) self lacks in its cohesiveness and continuity. In his incapacity to comprehend the primacy of disintegrated self and forms of the fundamental adaptations, the trauma victim imposes dysregulation and senseless relationships with the external world. As we understand, normal self is a platform which generates the affects, cognition, sensations, 
impulses, behaviour, and constitutes human actions and experience. We should, therefore, conceive that the interconnectedness of these elements which is severely disturbed in traumatized personality. Subsequently, the main structural principles of the self-cohesion and continuity which are closely associated became destabilised and represent the aftermaths of the traumatic experience [1]. The principles of self-cohesion are affected or impacted by disconnection of the self-wholeness into disintegrated parts (as in Table 2).

Table 2. Some aspects of disintegration of the self-disorganization caused by trauma.

\begin{tabular}{ll}
\hline Domains & Recurrent level \\
\hline $\begin{array}{l}\text { Fear of repetition of } \\
\text { trauma }\end{array}$ & $\begin{array}{l}\text { another trauma is coming; modified sense of invulnerability; despair; hopeless; unrealistic self-view; reasonable caution to } \\
\text { unrealistic fear }\end{array}$ \\
Shamefulness/Helplessness & $\begin{array}{l}\text { ashamed of being helpless; personal incompetence; rumination about future; failure to avoid the event; worries about coping; } \\
\text { the self is turned out }\end{array}$ \\
Survivor guilt & $\begin{array}{l}\text { responsibility for the event; self-blame for what has occurred; guiltiness of not reacting; destructive loss of power; fear of } \\
\text { deserved revenge; conflicts with moral injunctions; sense of being selfish; sense of undeserved fortune }\end{array}$ \\
$\begin{array}{l}\text { Fear of identification with } \\
\text { trauma }\end{array}$ & $\begin{array}{l}\text { the self placed in the traumatizer's role; frightening thoughts of harming; fear of death from unknown illness; irrational sense } \\
\text { of being fussed }\end{array}$ \\
The threat of loss & $\begin{array}{l}\text { sense of loss of honour or dignity; sense of possibility of never recovering; loss of body part; senseless of perception; fear of } \\
\text { with no cohesion and continuity; the self is defective and vulnerable }\end{array}$ \\
\hline
\end{tabular}

The essence of traumatised self-coherence is related to negative patters as a suspension of conscious, goal-directed, logical process of the self-continuity. The traumatised self is shaped by destructiveness or painful memories buried outside its cohesion and continuity within the space (world) as nothing worth is in. The ordinary self-structure is fissured in the ballast of personal being, unpleasant disruptions or distractions of the feeling of the existence. These elicit an extreme affect and dysfunctional behaviour, and intrapsychic responses as enormous reality-distorting defences. It is reasonable to hypothesise that the traumatised self fails to recognize or appropriately respond to negative selfrepresentation. It is also possible that the self-representation is highly unrealistic or may be disordered at some level.

Trauma victim with a severely disordered self-structure may find suicide as an 'emergency solution' in order to escape from the vulnerable and unhealthy self. Even when trauma is over, the disturbed self-at-worst has prolonged trauma-related condition as a form of distal exposure to an event(s) and suffers from consequences which manifest most clearly in the aftermath of trauma experience. Traumatised individual with the self-at-worst feels compromise without safety net or access to the emotional resources. In terms of practical reality and given the complexities in the ways trauma unfolds over time, we assume that the perceived-life-threat aspects of the trauma are often one of the strongest predictors of the risk of suicide for a trauma victim.

Depleted or shattered self has been afflicted with a sense of emptiness with a painful intensity or traumatic memories in form of flashbacks which imprints even further the destruction of the self as it is has 'nothing inside'. It is also evidenced that the individual's coping strategies are impaired due to inability to discharge tension and the drives of the inner conflicts. Severely traumatised individuals describe their disturbances of the self-structure: they feel they are falling apart, losing their bearings, or 'treading water in the middle of the ocean with nothing to hang on to', they may feel lost in space, or even have feeling they 'do not exist'. For the clinicians it is important to recognise the patient's use of negative terms when describing an experience of the fragmentation of the mind-body-self structure [3]. In some severe cases of dissociation caused by trauma, the patients would report dissociated parts of the body and that their body has become 'strange' or 'foreign' to them [9]. Trauma leads to the state of de-centering of the self, loss of groundedness and sense of ego-fragility, leaving scars in one's 'inner agency' of the psyche [1].

Fragmentation of the self-structure wholeness has consequence in the trauma victim's psychological stability, well-being, and psychic integration resulting in proneness to disintegrated personality as a whole [3, 14, 20, 44]. In many cases it is apparent that fragmentation of the self-structure is a fracture of the soul and spirit of the person, like a broken connection in the existential sense of the meaning and existence. Discontinuity of the self-cohesion shows a loss of strength, energy and autonomy [1, 14]. Moreover, the destruction of the self-structure results in the self-disunion, and/or dis-joining of the interrelated dimensions of the self.

The traumatised individual is unable to return to the pretrauma adaptive capacities, values, and goals due to unresolved and powerful inner conflicts. There is a 'broken system' for a new relationship, and coping style still rely on the mechanisms that have been used during the traumatic experience - 'survival skills'. Keeping trauma-related coping mechanisms the individual develops 'broken relations' of the here-and-now circumstances and the orderliness of daily living is profoundly altered in ways associated with a sense of the psychic disequilibrium. As the self is totally unadjusted to new life circumstances, trauma victim's survival skills become essential and powerful factor in formatting the individual's personality changes. This damages of the selfcohesion and continuity make trauma victim insecure, 
helpless and inadequate, hateful and hostile towards the own self-at-worst. Without ability for the self-continuity and continuation of the trauma-related coping mechanisms, the trauma victim is fearful, uncomfortable, horrified, vulnerable, and self-destructive [6].

Losing a sense of self during trauma makes it impossible for a person to re-build realisation of the self-concept up to the pre-trauma level. The distorted self-concept is far away from the meaningful recognition and cannot be conceptualised as an object worthy of praise. Due to the trauma, the sense of self is vague and altered (as it is in Table 3 ).

Table 3. Altered functions of the traumatised self.

\begin{tabular}{|c|c|}
\hline Domains & Types of alterations \\
\hline Fragmentation & $\begin{array}{l}\text { loss of integrated coherence and continuity to functional capacity; loss of control of the self-structure boundaries; loss of the self- } \\
\text { unity as a whole; loss of power to defend disintegration }\end{array}$ \\
\hline Discontinuity & $\begin{array}{l}\text { loss of ongoing sense of the self here-and-now circumstances; loss of the self-continuity with pre-trauma past; loss of capacity to } \\
\text { restore pre-trauma self }\end{array}$ \\
\hline Separation & $\begin{array}{l}\text { loss of emotional relations to the own self; loss of emotional ties with others, and others to the self; loss of connection to the self as } \\
\text { object; loss of body-mind connectedness; loss of connectedness between parts of the self; loss of sense of samenes }\end{array}$ \\
\hline Immobility & $\begin{array}{l}\text { loss of physical and mental dynamism; loss of psychic aliveness and vitality; loss of motivation and goal directed actions; generalised } \\
\text { loss of energy (fatigue, malaise); loss of ability to control the inner conflict drives from the traumatic past; loss of essential self- } \\
\text { vitality }\end{array}$ \\
\hline Loss of autonomy & $\begin{array}{l}\text { inability to discontinue the tie with traumatic past; guilt and self-blame; loss of capacity to self-regulate feelings and capacity to act } \\
\text { freely; development of the self-worthlessness; loss of groundedness; the self non-aliveness and non-presentness }\end{array}$ \\
\hline
\end{tabular}

The above stated alterations of the self are often out of consciousness and distant from the self, operate outside awareness and appear independent from any control by the self. Clinicians are agreeing that, in essence, the dissociation is operative and executive for non-realisation of the selfconcept $[1,3,13,18,27,47,48]$. It is a disruption in the usual integrated functions of consciousness, memory, identity, or perception of the environment, and disturbances may be sudden or gradual, transient or chronic [34]. In the event of non-realisation, the dissociation can be seen as the self's defensive process that reduces one's awareness of the psychological pain which causes the overwhelming emotions and dysfunctional state [1].

Because of the non-realisation, the self eliminates from awareness previous self-idealisation senses and develops disturbing discrepancies within its structure. The fact remains that altered self has to survive within its limitations in the post-traumatic growth; its further development, energy, power, and endurance - the limitations that halt the self in its continuity and cohesion. Such self is omnipresent stranger to the pre-trauma self what is always interfering, disturbing, and embarrassing - the self which can be described as the self-hate. Describing conflict between the pre - and posttrauma self seems quite pertinent for the trauma victims because it represents an aftermath of the trauma distant from their real self.

\section{Conclusion}

Since when the stress disorder for the first time has been recognised as an independent disorder and despite significant improvement in assessment and diagnostic evaluation, there has been continued controversy about the severity and complexity in regard to the changes of the trauma victim's personality by the trauma. This is in particular upon those who have been exposed to the prolonged or repeated traumatic experience $[12,14,20,26,47,55,61]$. In clinical practice it is evident that trauma is typically an interpersonal nature and occurs under circumstances where to escape was not possible due to the physical, psychological, environmental, or social constraints. It becomes almost compulsory that understanding of complex trauma emphasises the impact of a traumatic event(s) on the victim's self-concept and his view of others. The effects of trauma are in result when conscious and unconscious representation of the self is triggered by any reminder of the trauma causing no-discrepancy for the real and altered sense of self.

Seeing the self as a victim or as victimiser may interfere with one's trauma impact and the self is 'exposed' to the trauma even for long after the trauma is over. Even being functional and invulnerable before trauma, the trauma victim becomes so overwhelmed by the traumatic event(s) that the self transforms into the self-at-worst in which nothing else is meaningful than trauma experience and its aftermaths [1, 3 , $6,16,25]$. With such features, the self is fracturing its coherent sense of existence and continuity, or dissociates with an increased vulnerability to any forthcoming stress.

\section{References}

[1] Zepinic V. The Self and Complex Trauma, Xlibris Corporation, London, 2012

[2] Gersons BPR, Miranda Off. Coping with the aftermath of trauma, British Medical Journal, 5, 1038-1039, 2005

[3] van der Hurt O, Nijenhuis E, Steele K. The Haunted Self, WW Norton, New York, 2006

[4] van der Kolk BA, Fisler. Dissociation and the fragmentary nature of traumatic memories: Overview and explanatory study, Journal of Traumatic Stress, 8, 505-536, 1995 
[5] Wilson JP. The Posttraumatic Self, Routledge, New York, 2006

[6] Zepinic V. Healing Traumatic Memories: A case study, Dinamische Psychiatrie, 5-6, 279-287, 2008

[7] Gist R, Devilly GJ. Post-trauma debriefing: the road too frequently travelled, Lancet, 360, 741-742, 2002

[8] Creamer M, Burges P, McFarlane A. Posttraumatic stress disorder: Findings from the Australian national survey of mental health and well-being, Psychological Medicine, 31, $1237-1247,2001$

[9] Zepinic V. Persistence of 'Survival Skills' as a Risk Factor for Suicide in Severely Traumatized Individuals, International Journal of Emergency Mental Health and Human Resilience, 2, 552-558, 2015

[10] Zepinic V. The complexity of treating PTSD symptoms, paper presented at WPA International Conference, Istanbul, 2006

[11] Zepinic V. Suicidal risk with war-related posttraumatic stress disorder (Chapter 14), In Raphael B, Malak AE, (ed). Diversity and Mental Health in Challenging Times, TCMHC, Sydney, 2001

[12] Zepinic V. Hidden Scars: Understanding and Treating Complex Trauma, Xlibris Corporation, London 2011

[13] Schore AN. Affect Dysregulation and Disorders of the Self, WW Norton, New York, 2003

[14] Ulman RB, Brothers D. The Shattered Self: A Psychoanalytic Study of Trauma, The Analytic Press, Hillsdale, 1988

[15] Allen JG. Coping with trauma, $2^{\text {nd }}$ ed, American Psychiatric Publishing, Washington DC, 2005

[16] Courtois AC, Ford JD (ed). Treating Complex Traumatic Stress Disorder, The Guilford Press, New York, 2009

[17] Herman JL. Trauma and Recovery, Basic Books, New York, 1992

[18] Horowitz MJ, Zilberg N. Regressive alterations in the selfconcept, American Journal of Psychiatry, 140, 284-289, 1983

[19] Kartal D, Kiropoulos L. Effects of acculturative stress on PTSD, depressive, and anxiety symptoms among refugees resettled in Australia and Austria, European Journal of Psychotraumatology, 7, 28711, 2016

[20] van der Kolk BA, McFarlane AC, Weiseath L. Traumatic Stress, The Guilford Press, New York, 1996

[21] Zepinic V. Treatment Resistant Symptoms of Complex PTSD Caused by Torture During War, Canadian Social Science, 9, 26-32, 2015

[22] Kuzmanovski B. Foreword, In Zepinic V. Hidden Scars: Understanding and Treating Complex Trauma, Xlibris Corporation, London, 2011

[23] Cloitre M, Garvert DW, Brewin CR, Bryant RA, Maercker A. Evidence for proposed ICD-11 PTSD: a latent profile analysis, European Journal of Psychotraumatology, 4, 20706, 2013

[24] Zepinic V. Traumatic memory system, paper presented at WPA International Conference, Istanbul, 2006

[25] Foa EB, Rothbaum OB. Treating the Trauma of Rape, The Guilford Press, New York, 2000
[26] Horowitz MJ. Stress Response Syndrome, $4^{\text {th }}$ ed. Jason Aronson Inc., New York, 2001

[27] Ford JD, Courtois AC, Steele K, van der Hurt O, Nijenhius ERS. Treatment of complex posttraumatic dysregulation, Journal of Traumatic Stress, 5, 437-447, 2005

[28] Zepinic V. Defining a war-related psychological trauma: Is that one impossible task? The International Journal of Medicine, 3, 376-383, 2010

[29] Solomon MF, Siegel DJ (ed). Healing Trauma: Attachment, Mind, Body, and Brain, WW Norton, New York, 2003

[30] Krause ED, Mendelson T, Lynch TR. Childhood emotional and adult psychological distress: The mediating role of emotional inhibition, Child abuse and neglect, 27, 199-213, 2003

[31] ter Heide FJJ, Mooren TM, Kleber RJ. Complex PTSD and phased treatment in refugees: a debate piece, European Journal of Psychotraumatology, 7, 28687, 2016

[32] Beck AT, Emery G, Greenberg RL. Anxiety Disorders and Phobias: A Cognitive Perspective, Basic Books, New York, 2005

[33] Bisson JI, Ehlers A, Matthews R, Pilling S, Richard D, Turner S. Psychological treatments for chronic post-traumatic stress disorder, British Journal of Psychiatry, 190, 97-104, 2007

[34] American Psychiatric Association. Diagnostic and Statistical Manual of Mental Disorders, $5^{\text {th }}$ ed, APA, Arlington, 2013

[35] Brewin CR. Memory processes in post-traumatic stress disorder, International Review of Psychiatry, 13, 159-163, 2001

[36] Rubin DC. The Coherence of Memories for Trauma: Evidence from Posttraumatic Stress Disorder, Consciousness and cognition, 20, 857-865, 2011

[37] Sleijpen M, Haagen J, Mooren T, Kleber RJ. Growing from experience: an explanatory study of posttraumatic growth in adolescent refugees, European Journal of Psychotraumatology, 7, 28698, 2016

[38] Bremner JD. Acute and chronic responses to psychological trauma: Where do we go? American Journal of Psychiatry, $156,349-351,1999$

[39] Courtois AC. Complex trauma, complex reactions: Assessment and treatment, Psychotherapy: Theory, Research, Practice, Training, 41, 422-425, 2004

[40] Mikulincer M, Shaver PR. An attachment perspective on psychopathology, World Psychiatry, 11, 11-15, 2012

[41] Zepinic V. Psychological characteristics of war-related PTSD (Chapter 10), In Ferguson B, Barnes D (ed). Perspectives on Transcultural Mental Health, TCMH, Sydney, 1997

[42] Wilson JP, Drozdek B (ed). Broken Spirit, Brunner-Routledge, New York, 2004

[43] Phillips M, Frederick C. Healing the Divided Self, WW Norton, New York, 1995

[44] Wolfe E. Treating the Self, The Guilford Press, New York, 1999

[45] Zepinic V. Human Rights Violation and Chronic Symptoms of PTSD, Canadian Social Science, 2, 1-7, 2015 
[46] Zepinic V. Psychopathic Personality (Aetiology, Clinical, and Legal Issues), unpublished manuscript, 2016

[47] Bremner JD. Trauma, Memory, and Dissociation, American Psychiatric Press, Washington DC, 1997

[48] Steele K, van der Hurt O, Nijenhuis ERS. Phase oriented treatment of structural dissociation in complex traumatization: Overcoming trauma-related phobias, Journal of trauma and Dissociation, 6, 11-53, 2005

[49] Herman JL. Complex PTSD: A syndrome in survivors of prolonged and repeated trauma, Journal of Traumatic Stress, 3, 377-391, 1992

[50] Zepinic V: Treating the war-related complex trauma using Dynamic Therapy, The International Journal of Medicine, 3, 384-390, 2010

[51] Zlotnick C, Warshaw M, Shea MT, Allsworth J, Pearlstein T, Keller MB. Chronicity in posttraumatic stress disorder (PTSD) and predictors of course of comorbid PTSD in patients with anxiety disorders, Journal of Traumatic Stress, 12, 89-100, 1999

[52] Duckworth MP, Follete VM (ed). Retraumatisation: Assessment, Treatment, and Prevention, Routledge, New York, 2012

[53] Goldberg A. The Psychology of the self, International University Press, New York, 1978

[54] Joscelyne A, McLean S, Drobny J, Bryant RA. Fear of memories: the nature of panic in posttraumatic stress disorder, European Journal of Psychotraumatology, 3, 19084, 2012
[55] McNally RJ. Remembering Trauma, Harvard University Press, Cambridge, 2003

[56] Rubin DC, Bernsten D, Johansen MK. A Memory Based Model of Posttraumatic Stress Disorder: Evaluating Basic Assumptions Underlying of the PTSD Diagnosis, Psychology Review, 115, 985-1011, 2008

[57] van der Kolk, Roth SH, Pelcovitz D, Sunday S, Spinazzola J. Disorder of extreme stress: The empirical foundation of a complex adaptation to trauma, Journal of Traumatic Stress, 18, 389-399, 2005

[58] Briere J, Spinazzola J. Assessment of the sequelae of complex trauma. In Courtois CA, Ford JD (ed). Treating Complex Traumatic Stress, The Guilford Press, New York, 2009

[59] Burgess AW, Holstrom L. Rape trauma Syndrome, American Journal of Psychiatry, 131, 981-986, 1974

[60] Cloitre M. The “one size fits all” approach to trauma treatment: should we be satisfied? European Journal of Psychotraumatology, 6, 27344, 2015

[61] Cloitre M, Stolbach CB, Herman LJ, van der Kolk BA, et al. A developmental approach to complex PTSD: Childhood and adult cumulative trauma predictors of symptoms complexity, Journal of Traumatic Stress, 5, 399-408, 2009

[62] Gluck TM, Knefel M, Tran US, Lueger-Schuster B. PTSD in ICD-10 and proposed ICD-11 in elderly with childhood trauma: prevalence, factor structure, and symptoms profiles, European Journal of Psychotraumatology, 7, 29700, 2016 